\title{
Genetic and clinical features of patients with cystic fibrosis diagnosed after the age of 16
} years

King-Han Gan, Willem P Geus, Willem Bakker, Cornelis B H W Lamers, Harry G M Heijerman

\begin{abstract}
Background - Cystic fibrosis is usually diagnosed in childhood, but a number of patients are not diagnosed until adulthood. The aim of this study was to investigate whether patients diagnosed at an older age had a different genetic constitution, manifestations of disease, and prognosis from those diagnosed at an early age. Methods - Clinical data and results of lung function tests and DNA analysis of 143 adult patients with cystic fibrosis were entered into a computerised database. Patients diagnosed before their 16th birthday (early diagnosis, ED) were compared with those diagnosed at 16 years of age or older (late diagnosis, LD).
\end{abstract}

Results - Mean age of diagnosis of the ED group was $4 \cdot 6$ years compared with $27 \cdot 7$ years for the LD group. Mean (SD) percentage predicted pulmonary function was better for the LD group than for the ED group: forced expiratory volume in one second $\left(\mathrm{FEV}_{1}\right) \quad 72 \cdot 5 \quad(31 \cdot 1) \%$ and 52.0

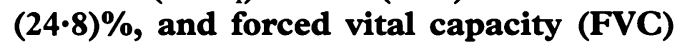
$89.8(25 \cdot 7) \%$ and $71.9(23 \cdot 0) \%$, respectively. Colonisation with Pseudomonas aemuginosa was present in $\mathbf{7 0} \%$ of the ED group and $24 \%$ of the LD group. In the ED group $81 \%$ had pancreatic insufficiency compared with only $12 \%$ of the LD group. None of the LD group was homozygous for $\Delta F 508$ compared with $58 \%$ of the ED group. In the LD group $72 \%$ were compound AF508 heterozygotes and $28 \%$ had two non- $\Delta$ F508 mutations.

Conclusions - Among this group of 143 adult patients with cystic fibrosis late diagnosis is caused mainly by delayed expression and mild progression of clinical symptoms. Late diagnosis is associated with milder pulmonary disease, less pancreatic insufficiency, and different cystic fibrosis mutations. Since mortality in cystic fibrosis depends on the progression of pulmonary disease, patients with a late diagnosis have a better prognosis than those diagnosed early.

(Thorax 1995;50:1301-1304)

Keywords: cystic fibrosis, late diagnosis, prognosis.

Cystic fibrosis is the most common serious genetic disorder among Caucasian populations with an incidence of about one in 2500 live births and with one in 25 persons as asymptomatic carriers. ${ }^{1}$ The disease is caused by mutations in the gene coding for the cystic fibrosis transmembrane conductance regulator (CFTR), a c-AMP dependent chloride channel. ${ }^{2-4}$

Most patients with cystic fibrosis in northern Europe have a mutation that causes the deletion of amino acid 508 (phenylalanine) of the CFTR protein, the so-called $\Delta F 508$ mutation. ${ }^{5}$ In The Netherlands the frequency of this mutation on chromosomes of patients with cystic fibrosis is $77 \cdot 1 \% .{ }^{6}$ More than 400 other mutations of the CFTR gene have now been found and most of them are rare. ${ }^{67}$

Cystic fibrosis is usually diagnosed in childhood, with up to $50 \%$ of patients presenting in the first year of life. ${ }^{8}$ Typical modes of presentation are meconium ileus, failure to thrive, recurrent pulmonary infections, diarrhoea, and steatorrhea. It may, however, be diagnosed in adult patients. ${ }^{8-11}$ Patients diagnosed late usually present with respiratory symptoms, or with male infertility due to congenital bilateral absence of the vas deferens (CBAVD). ${ }^{12}$

Diagnosis is confirmed by pilocarpine sweat iontophoresis, with chloride levels in sweat exceeding $70 \mathrm{mmol} / \mathrm{l}$. Diagnosis can also be made with electrophysiological tests of nasal $^{13}$ or rectal epithelium. ${ }^{14}$

In our centre for adult patients with cystic fibrosis we define late diagnosis (LD) as diagnosis at the age of 16 or older. Patients diagnosed before their 16 th birthday are considered to have an early diagnosis (ED). Almost $20 \%$ of our patients with cystic fibrosis were diagnosed after their 16th birthday. In this study we compared the characteristics of this group of LD patients with the characteristics of $\mathrm{ED}$ patients.

\section{Methods}

One hundred and forty three adult patients with cystic fibrosis who attended our clinic and for whom complete data (including DNA analysis) was available on 1 January 1995 were studied. Diagnosis was made by characteristic symptoms of cystic fibrosis, together with a chloride concentration in sweat of $>70 \mathrm{mmol} /$ 1. Sweat tests were usually performed at the referring hospital by various methods (classic pilocarpine test, chloride electrode, etc), and are not directly comparable. In a small number of patients the sweat test results were equivocal so electrophysiological tests of rectal epithelium 
were performed to confirm the diagnosis of cystic fibrosis. ${ }^{14}$

One hundred and thirty eight patients were Dutch, two were of Italian-Dutch descent, two were of Indonesian descent and one was of Chinese descent. There were 13 sets of siblings in our sample: a family of four, a family of three, and 11 sibling pairs, among them one pair of twins.

Demographic data including age, sex, age at diagnosis, presenting signs, and smoking history were taken from patients' charts. Age at diagnosis was determined as the age on the day of a first positive sweat test. For height and weight the values measured at the last clinic visit were used. Body mass index was calculated as weight/height ${ }^{2}$ (weight in kilograms, height in metres). The presenting signs were those that caused the patient to seek medical attention and were categorised as follows: gastrointestinal complaints including diarrhoea, steatorrhoea, vomiting and abdominal pain; meconium ileus and rectal prolapse; ear, nose and throat complaints including nasal polyps and recurrent or chronic sinusitis.

Lung function tests were regularly performed in all patients and the best values for forced expiratory volume in one second $\left(\mathrm{FEV}_{1}\right)$ and forced vital capacity (FVC) over the previous year was used. The values were compared with reference values of the European Respiratory Society. ${ }^{15}$ An age-independent yearly decline in $\mathrm{FEV}_{1}$ was calculated by dividing the difference between predicted $\mathrm{FEV}_{1}$ and actual $\mathrm{FEV}_{1}$ (expressed as a percentage of reference values) by age.

Patients with consecutive sputum cultures growing Pseudomonas aeruginosa for at least six months were considered to be colonised with this microorganism.

Pancreatic insufficiency was considered to be present when patients had a faecal fat excretion of $>10 \%$ fat intake during three day fat balance studies, or when gross steatorrhoea necessitated the use of pancreatic enzyme supplements, and diabetes mellitus (DM) was considered to be present when insulin was needed to control a patient's blood glucose concentration.

DNA was analysed for the following mutations: E60X, R117H, A455E, $\Delta \mathrm{I} 507, \Delta \mathrm{F} 508$, G542X，S549N，G550X，G551D，R553X, R560T, R1162X, S1251N, W1282X, $\mathrm{N} 1303 \mathrm{~K}, 621+1 \mathrm{G} \rightarrow \mathrm{T}, 1717-1 \mathrm{G} \rightarrow \mathrm{A}$. These mutations represent $80 \%$ of the expected cystic fibrosis mutations in The Netherlands. DNA testing was done at the University of Groningen, Department of Medical Genetics and at
University Hospital Rotterdam, Department of Clinical Genetics.

All data were entered into a computerised database. Continuous variables were compared by a two tailed unpaired $t$ test. Categorical variables were compared using the $\chi^{2}$ test. A p value of $<0.05$ was considered significant.

\section{Results}

Table 1 summarises the demographic data of the patient population. There were 118 patients with ED and 25 with LD. The mean age of the ED and LD patients was 26.8 and $35 \cdot 7$ years, respectively. The mean age of diagnosis in the ED group was 4.6 years ( 31 patients were diagnosed in the first year of life), and $27 \cdot 7$ years in the LD group. The mean height was below average for both men and women in the ED group: average height for men was around the 15th percentile and for women the 30th percentile for height compared with the normal Dutch population. ${ }^{16}$ In the LD group both men and women were around the 50th percentile for height. Body mass index (BMI) was a little higher in the LD group $(p=0.05)$, although for both groups it fell in the normal range $(20.2(2.4)$ in the ED group and 21.4 $(2 \cdot 8)$ in the LD group).

In the ED group $47 \%$ presented with recurrent respiratory tract infections, $45 \%$ with abnormal stools and other gastrointestinal tract symptoms, $5 \%$ with meconium ileus, $2 \cdot 5 \%$ with rectal prolapse, $14 \%$ with poor growth or weight gain, and $6 \%$ with ENT symptoms such as nasal polyps or recurrent sinusitis. In $14 \%$ diagnosis was made because of a sibling or family member with cystic fibrosis (because many patients had more than one presenting symptom, the total exceeds $100 \%$ ). In the LD group the presenting signs were recurrent respiratory tract infections in $92 \%$, gastrointestinal tract complaints in $8 \%$, one patient (4\%) presented with male infertility, and one patient (4\%) with oesophageal varices. In $24 \%$ the diagnosis was made because of cystic fibrosis in a sibling.

DNA of all patients was analysed for CFTR mutations. In the ED group the $\Delta \mathrm{F} 508$ mutation was found on $74 \cdot 2 \%$ of all cystic fibrosis chromosomes tested. Sixty eight patients ( $47 \%$ ) were homozygous for the $\Delta F 508$ mutation (table 2). In the LD group the frequency of the $\Delta \mathrm{F} 508$ mutation was $36.0 \%$, and none of the patients was homozygous for this mutation (table 2). The difference between the two groups is highly significant $(p<0.0001)$.

Table 1 Basic characteristics of early and late diagnosis groups

\begin{tabular}{llll}
\hline & $\begin{array}{l}\text { Early diagnosis } \\
(n=118)\end{array}$ & $\begin{array}{l}\text { Late diagnosis } \\
(n=25)\end{array}$ & $p$ \\
\hline Men/women (abs. number (\%)) & $62 / 56(53 / 47)$ & $12 / 13(48 / 52)$ & NS \\
Mean age (range) (years) & $26 \cdot 8(15 \cdot 8-42 \cdot 7)$ & $35 \cdot 7(21 \cdot 4-55 \cdot 6)$ & $<0 \cdot 005$ \\
Mean age at diagnosis (range) (years) & $4 \cdot 6(0 \cdot 0-15 \cdot 9)$ & $27 \cdot 7(16 \cdot 9-43 \cdot 4)$ & $<0 \cdot 005$ \\
Mean height (height percentile) men & $1 \cdot 75(12 \cdot 9)$ & $1 \cdot 83(53 \cdot 9)$ & $<0 \cdot 05$ \\
Mean height (height percentile) women & $1 \cdot 66(33 \cdot 0)$ & $1 \cdot 68(44 \cdot 0)$ & NS \\
BMI & $20 \cdot 2(2 \cdot 4)$ & $21 \cdot 4(2 \cdot 8)$ & $<0 \cdot 05$ \\
\hline
\end{tabular}

$\mathrm{BMI}=$ body mass index 
Table 2 Presence of $\Delta F 508$ mutation in 136 patients

\begin{tabular}{llll}
\hline & All patients & Early diagnosis & Late diagnosis \\
\hline$\Delta \mathrm{F} 508$ 2X & $68(47 \%)$ & $68(58 \%)$ & $0(0 \%)$ \\
$\Delta \mathrm{F} 508$ 1X & $57(40 \%)$ & $39(33 \%)$ & $18(72 \%)$ \\
Two other mutations & $18(13 \%)$ & $11(9 \%)$ & $7(28 \%)$ \\
$\Delta$ F508 frequency & $67 \cdot 3 \%$ & $74.2 \%$ & $36.0 \%$ \\
\hline
\end{tabular}

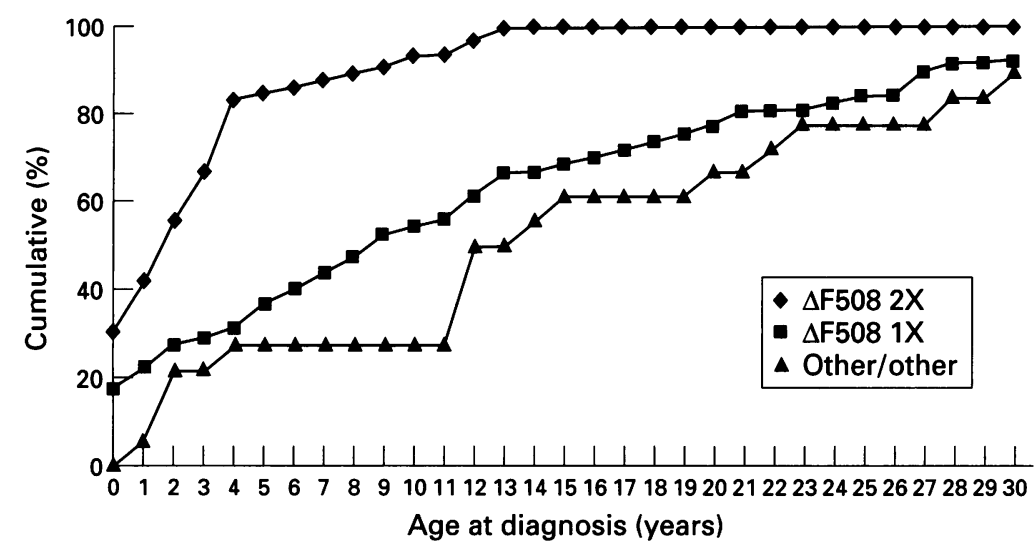

Cumulative percentages of patients with cystic fibrosis diagnosed by age and by the presence of $\triangle F 508$ mutation.

Table 3 CFTR mutations in 278 chromosomes of adult cystic fibrosis patients

\begin{tabular}{|c|c|c|c|c|}
\hline & \multicolumn{2}{|c|}{$\begin{array}{l}\text { Early diagnosis } \\
(n=118)\end{array}$} & \multicolumn{2}{|c|}{$\begin{array}{l}\text { Late diagnosis } \\
(n=25)\end{array}$} \\
\hline & $n$ & $\%$ & $n$ & $\%$ \\
\hline$\Delta \mathrm{F} 508^{\mathrm{s}}$ & 175 & $74 \cdot 2$ & 18 & $36 \cdot 0$ \\
\hline $\mathrm{A} 455 \mathrm{E}^{\mathrm{m}}$ & 12 & $5 \cdot 1$ & 14 & $28 \cdot 0$ \\
\hline $1717-1^{\mathrm{s}}$ & 6 & $2 \cdot 5$ & 1 & $2 \cdot 0$ \\
\hline G542X & 4 & $1 \cdot 7$ & - & \\
\hline W1282Xs & 3 & $1 \cdot 3$ & - & \\
\hline R553X & 1 & 0.4 & 1 & $2 \cdot 0$ \\
\hline S1251N & 2 & $0 \cdot 8$ & - & \\
\hline $\mathrm{N} 1303 \mathrm{~K}^{\mathrm{s}}$ & 1 & 0.4 & - & \\
\hline E60X & 1 & 0.4 & 3 & $6 \cdot 0$ \\
\hline Not identified & 31 & $13 \cdot 2$ & 13 & $26 \cdot 0$ \\
\hline Total & 236 & & 50 & \\
\hline
\end{tabular}

Mutations not found: R117H, $\Delta \mathrm{I} 507$, S549N, G550X, G551D R560T, R1162X, 621 + 1G $\rightarrow$ T.

Mutations marked ' $\mathrm{s}$ ' are considered severe, those marked ' $\mathrm{m}$ ' are considered mild. ${ }^{29}$

The influence of the presence of the $\Delta \mathrm{F} 508$ mutation on the age of diagnosis is shown in the figure. All $\Delta \mathrm{F} 508$ homozygotes were diagnosed by age 13 , whereas $39 \%$ of patients not bearing the $\Delta \mathrm{F} 508$ mutation were diagnosed at an age older than 16 years. The frequency of all CFTR mutations found is listed in table 3. The A455E mutation was relatively frequent in the $\mathrm{LD}$ group. In the $\mathrm{ED}$ group

Table 4 Mean (SD) pulmonary parameters expressed as a percentage of predicted values

\begin{tabular}{llll}
\hline & $\begin{array}{l}\text { Early diagnosis } \\
(n=118)\end{array}$ & $\begin{array}{l}\text { Late diagnosis } \\
(n=25)\end{array}$ & $p$ \\
\hline FEV $_{1}$ & $52 \cdot 0(24 \cdot 8)$ & $72.5(31 \cdot 1)$ & $<0.005$ \\
FVC & $71.9(23 \cdot 0)$ & $89 \cdot 8(25 \cdot 7)$ & $<0.005$ \\
Yearly decline in FEV & $1 \cdot 82(0 \cdot 97)$ & $0 \cdot 74(0.88)$ & $<0.005$ \\
No. (\%) colonised with $P$ aeruginosa & $83(70.3 \%)$ & $6(24 \%)$ & $<0.005$ \\
\hline
\end{tabular}

$\mathrm{FEV}_{1}=$ forced expiratory volume in one second; $\mathrm{FVC}=$ forced vital capacity.

Table 5 Number of patients (\%) with non-pulmonary disease symptoms

\begin{tabular}{llll}
\hline & $\begin{array}{l}\text { Early diagnosis } \\
(n=118)\end{array}$ & $\begin{array}{l}\text { Late diagnosis } \\
(n=25)\end{array}$ & $p$ \\
\hline Pancreatic insufficiency & $96(81 \%)$ & $3(12 \%)$ & $<0 \cdot 005$ \\
Diabetes mellitus & $17(14 \%)$ & $2(8 \%)$ & NS \\
\hline
\end{tabular}

$13 \cdot 2 \%$ of mutations could not be identified compared with $26 \cdot 0 \%$ in the LD group.

Table 4 lists the results of lung function tests for the two groups. In the ED group $\mathrm{FEV}_{1}$ and FVC were significantly lower than in the LD group, despite the average higher age of the latter group. In both groups of patients the decline in $\mathrm{FEV}_{1}$ was faster than in the general population. However, the average annual decline in $\mathrm{FEV}_{1}$ was more than twice as large in ED patients than in LD patients. In the ED group a decline of $\mathrm{FEV}_{1}$ to $30 \%$ is predicted by 38.3 years and for the LD group at 94.9 years. When the $\mathrm{FEV}_{1}$ falls below $30 \%$ the likelihood of death within two years is increased and serious disability can be anticipated. ${ }^{17}$

In the ED group colonisation with Pseudomonas aeruginosa was present in 83 patients $(70.3 \%)$ compared with six patients $(24 \%)$ in the LD group $(\mathrm{p}<0.005)$.

There was one active smoker in the ED group, and one active and seven former smokers in the LD group.

Non-pulmonary disease symptoms are summarised in table 5. Pancreatic insufficiency was present in 96 patients $(81 \%)$ of the ED group compared with only three $(12 \%)$ in the LD group $(p<0.005)$. Diabetes mellitus occurred in 17 patients (14\%) in the ED group and in two $(8 \%)$ of the LD group (NS). All ED patients with diabetes had an exocrine pancreatic insufficiency. In the LD group one of the patients with diabetes had an exocrine pancreatic insufficiency while in the other patient diabetes was associated with the use of oral corticosteroids.

\section{Discussion}

This study describes the clinical and genetic features of patients in whom cystic fibrosis was diagnosed late compared with those in whom it was diagnosed early. Late diagnosis appears to be not just a case of doctor or patient delay, but to constitute a separate patient group with a distinct genetic constitution and often milder pulmonary and non-pulmonary disease symptoms.

In earlier descriptions of groups of adult patients with cystic fibrosis $3 \cdot 5-21 \%$ were diagnosed at 16 years or older. ${ }^{818-22}$ In these reports on adult patients late diagnosis was not associated with milder disease. In fact, it was found that patients diagnosed at an early age generally did better than those diagnosed at a later age $^{2324}$ or there was no difference. ${ }^{1922}$ However, our study shows that late diagnosis does not necessarily have to be detrimental to prognosis.

There are a number of reasons for late diagnosis. Firstly, mild or absent symptoms may delay a patient seeking medical attention. Secondly, a physician may not recognise cystic fibrosis, especially when the presenting symptoms are atypical. Finally, there may be problems in the diagnosis of cystic fibrosis as, for example, when there are repeated normal or borderline sweat tests. ${ }^{25} 26$

Most of those diagnosed early presented with a combination of gastrointestinal and pul- 
monary symptoms, while in the late diagnosis group most were diagnosed because of recurrent pulmonary infections or because cystic fibrosis was found in a sibling. Gastrointestinal symptoms rarely led to the diagnosis of cystic fibrosis in this group. Until now the cystic fibrosis genotype was not predictive for pulmonary function or for prognosis. ${ }^{27}$ Our results make it much more likely that there is a link between CFTR mutations and the severity of pulmonary disease. Among our patients all $\Delta \mathrm{F} 508$ homozygotes were in the early diagnosis group who had more severe pulmonary and non-pulmonary disease. Most of those diagnosed at 16 years or older were pancreatic sufficient, which is closely related to the type of CFTR mutation. ${ }^{2829}$ The A455E mutation was frequently found among this group of patients and preliminary studies indicate that this mutation, known to be related to pancreatic sufficiency, ${ }^{29}$ may be associated with mild pulmonary disease. ${ }^{30}$ It seems that other CFTR mutations (some of which are still unidentified) in patients diagnosed late are associated with pancreatic sufficiency and also with mild pulmonary disease. It is doubtful that pancreatic and pulmonary status are determined entirely by independent genetic factors. ${ }^{28}$

The authors thank Drs Scheffer and Van der Hout (Department of Medical Genetics, University of Groningen) and Drs Halley and Van den Ouweland (Department of Clinical Genetics, University Hospital Rotterdam) for performing the DNA analysis.

1 Lewis PA. The epidemiology of cystic fibrosis. In: Hodson ME, Geddes DM, ed. Cystic fibrosis. 1st edn. London: Chapman and Hall, 1995:1-13.

2 Rommens JM, Iannuzzi MC, Kerem BS, Drumm ML, Melmer G, Dean $M$, et al. Identification of the cystic fibrosis gene: chromosome walking and jumping. Science 1989;245:1059-65.

3 Riordan JR, Rommens JM, Kerem BS, Alon N, Rozmahe $\mathrm{R}$, Grzelczak Z, et al. Identification of the cystic fibrosis gene: cloning and characterization of complementary DNA. Science 1989;245:1066-73.

4 Kerem BS, Rommens JM, Buchanan JA, Markiewicz D Cox TK, Chakravarti A, et al. Identification of the cystic fibrosis gene: genetic analysis. Science 1989;245:1073-80.

5 Population analysis of the major mutation in cystic fibrosis Hum Genet 1990;85:391-453.

6 Cystic Fibrosis Genetic Analysis Consortium. Population variation of common cystic fibrosis mutations. Hum Mutat variation of comm.

7 Tsui LC. Mutations and sequence variations detected in the cystic fibrosis transmembrane conductance regulato (CFTR) gene: a report from the Cystic Fibrosis Genetic Analysis Consortium. Hum Mutat 1992;1:197-203.

8 Penketh AR, Wise A, Mearns MB, Hodson ME, Batten JC. Cystic fibrosis in adolescents and adults. Thorax 1987;42. 526-32.
9 Van Biezen P, Overbeek SE, Hilvering C. Cystic fibrosis in a 70 year old woman. Thorax 1992;47:202-3.

$10 \mathrm{Su}$ CT, Bearnblossom B. Typical cystic fibrosis in an elderly woman. Am f Med 1989;86:701-3.

11 Hunt B, Geddes DM. Newly diagnosed cystic fibrosis in middle and later life. Thorax 1985;40:23-6.

12 Anguiano A, Oates RD, Amos JA, Dean M, Gerrard B, Stewart $\mathrm{C}$, et al. Congenital bilateral absence of the vas deferens. A primarily genital form of cystic fibrosis. $\mathfrak{F} A M A$ 1992;267:1794-7.

13 Alton EW, Currie D, Logan-Sinclair R, Warner JO, Hodson ME, Geddes DM. Nasal potential difference: a clinical diagnostic test for CF. Eur Respir $\mathcal{F}$ 1990;3:922-6.

14 Veeze HJ, Sinaasappel M, Bijman J, Bouquet J, De Jonge HR. Ion transport abnormalities in rectal suction biopsies from children with cystic fibrosis. Gastroenterology 1991; 101:398-403.

15 Quanjer PH, Tammeling GJ, Cotes JE, Pedersen OF, Peslin $R$, Yernault JC. Lung volumes and forced ventilatory flows. Report of Working Party on Standardization of Lung Function Tests, European Community for Steel and Coal. Official Statement of the European Respiratory Society. Eur Respir f 1993;16(Suppl):5-40.

16 Van Wieringen JC, Roede M, Wit JM. Groeidiagrammen voor patientenzorg [Growth charts for patient care] Tijdschr Kindergeneesk 1985;53:147-52.

17 Kerem E, Reisman J, Corey M, Canny GJ, Levison $H$ Prediction of mortality in patients with cystic fibrosis. $N$ Engl F Med 1992;326:1187-91.

18 di Sant'Agnese PA, Davis PB. Cystic fibrosis in adults. 75 cases and a review of 232 cases in literature. Am $\mathcal{F}$ Med 1979;66:121-32.

19 Huang NN, Schidlow DV, Szatrowski TH, Palmer J, LarayaCuasay LR, Yeung W, et al. Clinical features, survival rate, and prognostic factors in young adults with cystic fibrosis Am $\mathcal{F}$ Med 1987;82:871-9.

20 Shwachman H, Kowalski M, Khaw KT. Cystic fibrosis: a new outlook. 70 patients above 25 years of age. Medicine 1977;56:129-49.

21 Stern RC, Boat TF, Doershuk CF, Tucker AS, Miller RB, Matthews LW. Cystic fibrosis diagnosed after age 13. Ann Intern Med 1977;87:188-91.

22 Burke W, Aitken ML, Chen SH, Scott CR. Variable severity of pulmonary disease in adults with identical cystic fibrosis mutations. Chest 1992;102:506-9.

23 Orenstein DM, Boat TF, Stern RC, Tucker AS, Charnock EL, Matthews LW, et al. The effect of early diagnosis and treatment in cystic fibrosis. Am $\mathcal{F}$ Dis Child 1977;131 973-5.

24 Dankert-Roelse JE, Te Meerman GJ, Martijn A, Ten Kate LP, Knol K. Survival and clinical outcome in patients with cystic fibrosis, with or without neonatal screening. $\mathcal{F}$ Pediatr 1989;114:362-7.

25 Augarten A, Kerem BS, Yahav Y, Noiman S, Rivlin Y, Ta $A$, et al. Mild cystic fibrosis and normal or borderline sweat test in patients with the $3849+10 \mathrm{~kb} \mathrm{C} \rightarrow \mathrm{T}$ mutasweat test in patients with the
tion. Lancet 1993;342:25-6.

26 Veeze HJ, Van den Ouweland AMW, Timmers-Reeker AJM Scheffer $\mathrm{H}$, Bijman J, Sinaasappel $\mathrm{M}$, et al. Increased incidence of $\Delta \mathrm{F} 508 / \mathrm{A} 455 \mathrm{E}$ patients by intestinal curren measurements in case of borderline or even high norma sweat tests. (Abstract). Pediatr Pulmonol 1994;Suppl 10: 220.

27 Cystic Fibrosis Genotype-Phenotype Consortium. Correlation between genotype and phenotype in patients with cystic fibrosis. N Engl $¥$ Med 1993;329:1308-13.

28 Santis G, Osborne L, Knight RA, Hodson ME. Independent genetic determinants of pancreatic and pulmonary status genetic determinants of pancreatic and pulm
in cystic fibrosis. Lancet 1990;336:1081-4.

29 Kristidis P, Bozon D, Corey M, Markiewicz D, Rommens J, Tsui LC, et al. Genetic determination of exocrine pancreatic function in cystic fibrosis. Am $\mathcal{F}$ Hum Genet 1992 50:1178-84.

30 Gan KH, Heyerman HGM, Bakker W. Correlation between genotype and phenotype in patients with cystic fibrosis (letter). N Engl f Med 1994;330:865-6. 